\title{
DUAL-BAND MONOPOLE ANTENNA WITH STAGGER-TUNED ARMS FOR BROADBANDING
}

\author{
M. J. Ammann* and R. Farrell** \\ Centre for Telecommunications Value-chain driven Research \\ *School of Electronic \& Communications Engineering \\ Dublin Institute of Technology, Kevin St. Dublin 8 \\ IRELAND \\ **Electronic Engineering Department \\ National University of Ireland \\ Maynooth Co. Kildare \\ IRELAND
}

\begin{abstract}
The paper describes a dual-band miniaturized printed monopole for integration in modern wireless systems. The printed monopole is augmented with two arms, resonant at slightly different frequencies, providing a broadened response for the upper band. The achieved bandwidth for the high band is $36 \%$. These antennas are proposed for the emerging dual-mode multi-band WLAN transceivers, which operate over a wide range of bands as dictated by national authorities. Measured and simulated data including return loss, antenna gain and radiation patterns are presented. The numerical method employed was the finite integration technique.
\end{abstract}

\section{INTRODUCTION}

Many innovative wireless systems are currently developing in frequency bands that have been set aside by national authorities for licence free use. The two key bands in Europe being the 2.4 to $2.5 \mathrm{GHz}$ ISM band and 5.15 to $5.88 \mathrm{GHz}$ bands. The $5 \mathrm{GHz}$ bands consist of frequencies assigned for licence free use between 5.15 and $5.35 \mathrm{GHz}$ and between 5.47 and $5.88 \mathrm{GHz}$, with 5.73 to $5.88 \mathrm{GHz}$ allocated for ISM use. The US bands are slightly different, but not extending outside the European bands. In Japan, $4.9-5.0 \mathrm{GHz}$ and $5.03-5.091 \mathrm{GHz}$ are used for the upper band. Dual-mode multiband WLAN transceivers must now operate across all theșe bands. The antenna bandwidth demanded to cover all these systems is $100 \mathrm{MHz}$ in the low band $(2.4-2.5 \mathrm{GHz})$ and $980 \mathrm{MHz}$ in the upper band (4.9-5.88 GHz).

\section{BACKGROUND}

Dual band monopoles have recently been reported which cover frequencies employed by WLAN systems in the US [1]. Two branch monopoles have been employed in printed form but do not have sufficient bandwidth for the high band. These provide about $700-800 \mathrm{MHz}$ which is slightly narrow and may be prone to tolerance problems, when low cost substrates are used. FR4 is commonly used because of its low cost, but this substrate suffers badly with lack of stability of permittivity and loss tangent with frequency [2].

\section{ANTENNA GEOMETRY}

The antenna geometry and coordinate system is shown in Figure l. The monopole is printed on one side of the substrate and fed by a microstrip feedline of width $w=2.3 \mathrm{~mm}$. The feedline is excited by an SMA launch connector. The groundplane is located at the other side of the laminate as shown. The dimensions of the antenna are $h_{1}=23.5 \mathrm{~mm}$, $h_{2}=4.3 \mathrm{~mm}, h_{3}=2.5 \mathrm{~mm}, h_{4}=4 \mathrm{~mm}, w_{1}=5.9 \mathrm{~mm}, w_{2}=5.3 \mathrm{~mm}$. The substrate dimensions are $l=80 \mathrm{~mm}$ and $W=60 \mathrm{~mm}$ with the groundplane extending $28 \mathrm{~mm}$ from the bottom edge. The relative permittivity and loss tangent are 4.3 and 0.02 , respectively at $2 \mathrm{GHz}$. The board thickness is $1.52 \mathrm{~mm}$ and the metallization thickness is 35 microns ( $\mathrm{oz} / \mathrm{sq} . \mathrm{ft}$ ). 


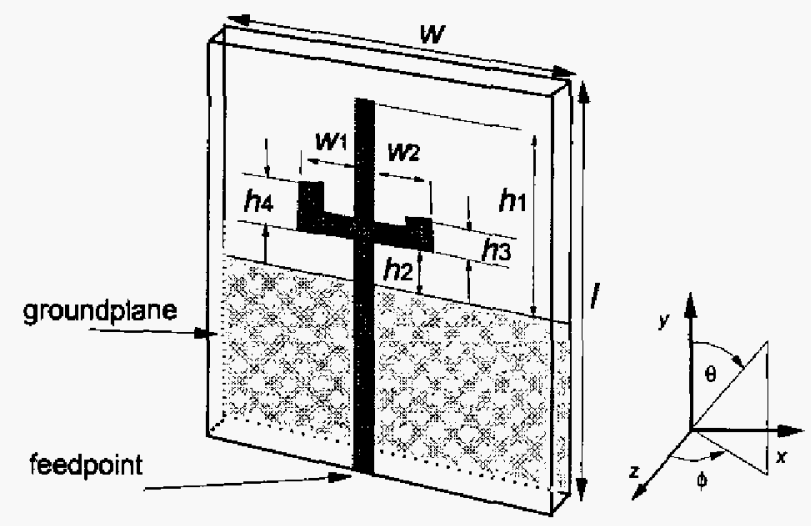

Figure 1. Geometry of the microstrip-fed dual-band printed monopole with stagger tuned arms for upper band.

\section{MEASUREMENTS AND SIMULATION}

The measured return loss was greater than $10 \mathrm{~dB}$ from $2.15-2.75 \mathrm{GHz}$ and from $4.55-5.91 \mathrm{GHz}$ which is shown in Figure 2. The simulated response, carried out using finite integration [3], is in reasonable agreement. The resonances for each of the monopole arms were found using this technique and were $4.87 \mathrm{GHz}$ and $5.5 \mathrm{GHz}$ for the long and short arms respectively. (see Figure 3)

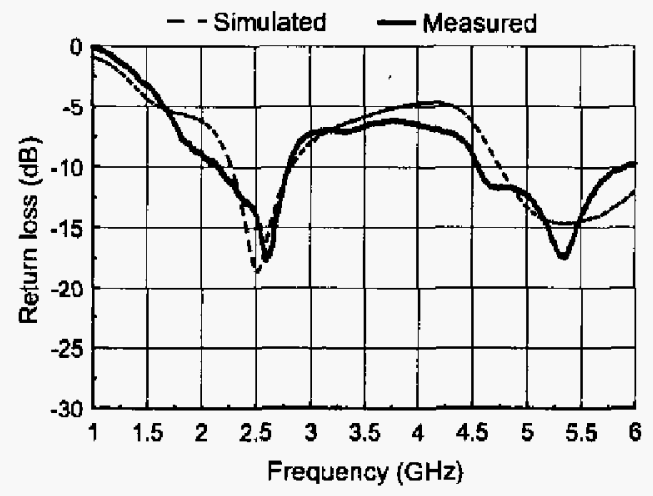

Figure 2. Measured and simulated return loss for the dual-band printed antenna.

\section{RADIATION PATTERNS}

The measured radiation patterns are normalised to maximum gain and are illustrated in Figure 4 . The maximum gain was found to be $3.1 \mathrm{dBi}$ and $2.8 \mathrm{dBi}$ at 2.45 and $5 \mathrm{GHz}$ respectively. Numerical analysis determined the radiation efficiency to be $80 \%$ and $76 \%$. The reduction in maximum gain by using this low-cost laminate compared to low-loss laminate is about $0.8 \mathrm{~dB}(2.45 \mathrm{GHz})$ and $1.4 \mathrm{~dB}(5.2 \mathrm{GHz})$, but the increased substrate losses contribute significantly to the enhanced bandwidth. 


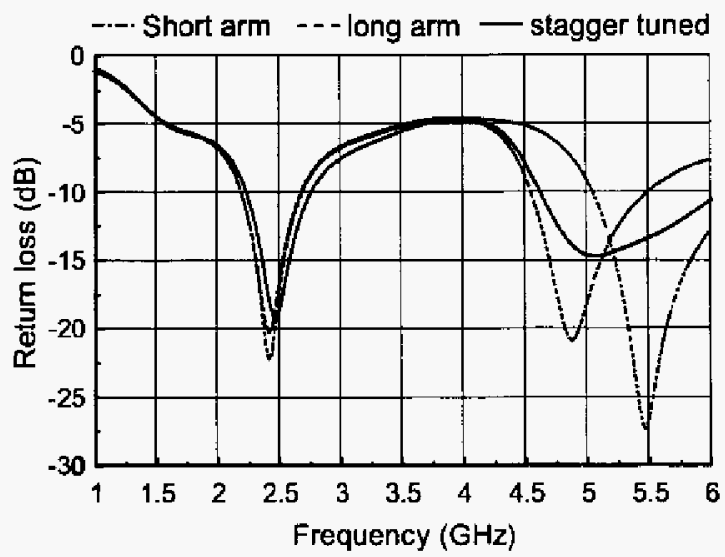

Figure 3. Simulated return loss for the monopole with (a) short arm, (b) long arm and (c) both arms stagger tuned.
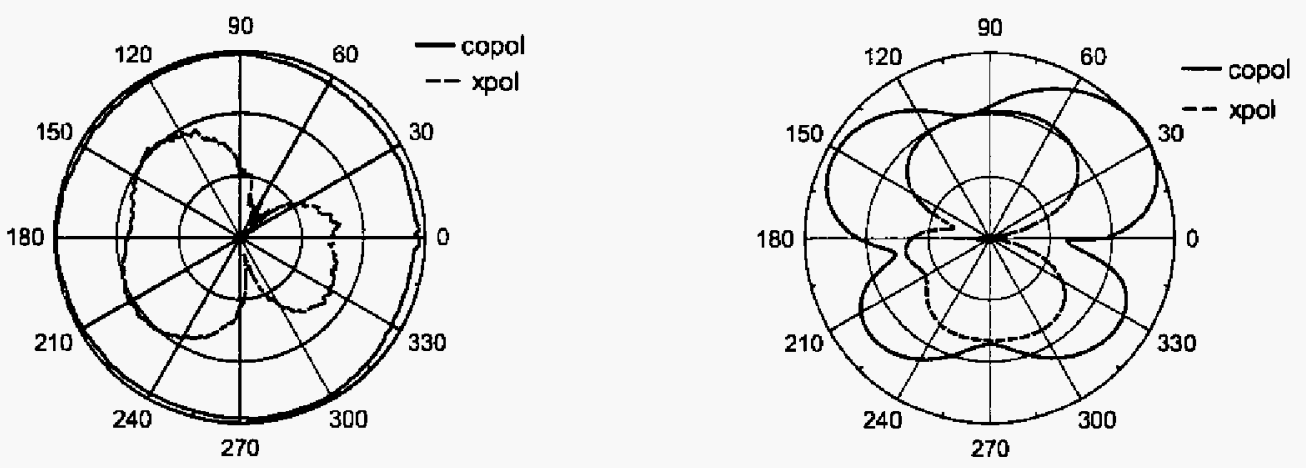

Figure 4 Radiation pattern for the $\phi, \theta=0(\mathrm{xz})$ plane at $2.5 \mathrm{GHz}$ (left) and $5.2 \mathrm{GHz}$ (right)
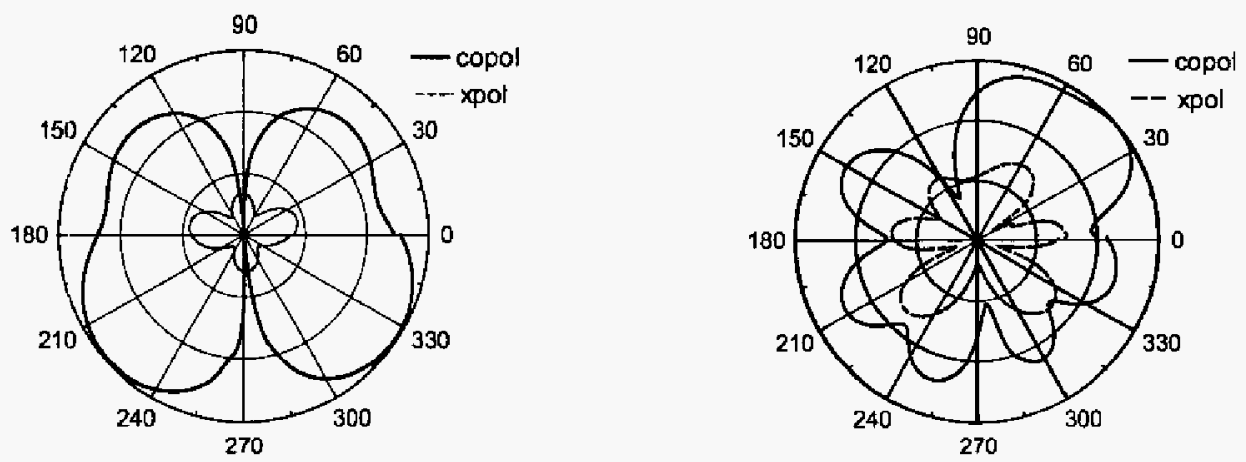

Figure 4 Radiation pattern for the $\theta, \phi=90$ (xy) plane at $2.5 \mathrm{GHz}$ (left) and $5.2 \mathrm{GHz}$ (right) 

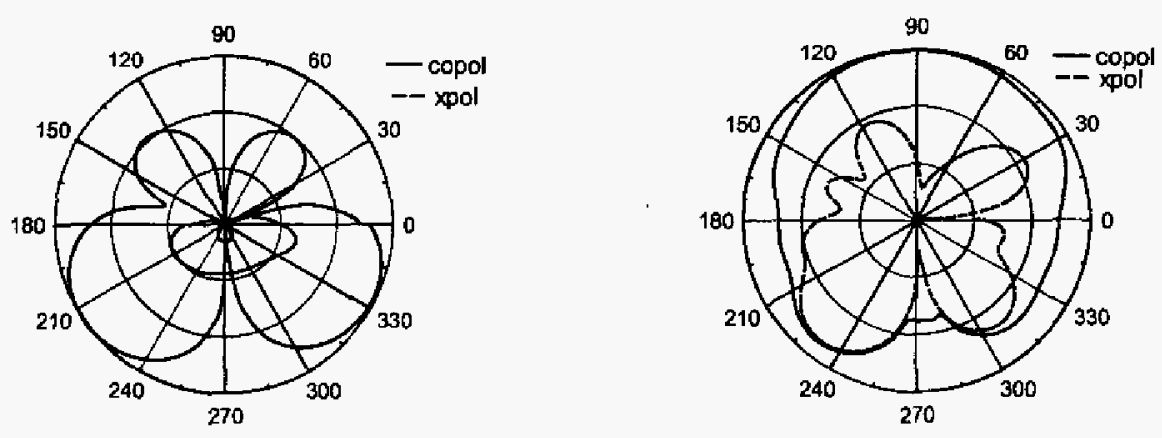

Figure 4 Radiation pattern for the $\theta, \phi=0$ (yz) plane at $2.5 \mathrm{GHz}$ (left) and $5.2 \mathrm{GHz}$ (right)

\section{CONCLUSIONS}

Dual-band printed monopoles with enhanced bandwidth can be realised by adding stagger-tuned arms to the printed monopole. A $36 \%$ fractional impedance bandwidth is obtained for the upper band which is sufficient to cover all wireless bands as dictated by different national authorities.

\section{ACKNOWLEDGEMENTS}

This work was supported by Science Foundation Ireland.

\section{REFERENCES}

I. Yeh S. H and Wong K. L,

Integrated $\mathrm{F}$ shaped monopole antenna for 2.4/5.2 dual-band operation

Microwave optical Technology Letters, 2002, (34), 24-26.

2. Ammann M. J,

A Comparison of Some Low-cost Laminates for Antennas operating in the $2.45 \mathrm{GHz}$ ISM Band, IEE Colloq. Dig., 206, London, 1998, pp. 3.1-3.5.

3. M Clemens and T. Weiland,

Discrete Electromagnetism with the Finite Integration Technique,

J. Electromagnetic Waves \& Propagat., PIER Monograph Series, 2001. 